\title{
Have We Found the Holy Grail? Theory of Mind as a Unifying Construct
}

\author{
Jeffrey H. Boyd
}

Published online: 3 May 2008

(C) Blanton-Peale Institute 2008

\begin{abstract}
Theory of Mind (ToM) refers to a person's ability to understand that another person has his or her own unique way of thinking and feeling. ToM is a well-known and rapidly expanding field of research in the neurosciences, cognitive, social sciences, evolution, and brain imaging. This review article expands ToM into areas where there has not yet been research. We propose that ToM could illuminate the relationship between religion/spirituality and health, and could provide the lingua franca for the hundreds of schools of psychotherapy. We discern two different kinds of spirituality: personal versus impersonal. Empathy is central to ToM research and is also central to mental health training and practice. ToM illuminates familiar topics in a new light. For example ToM reveals a close link between psychology and spirituality in self-efficacy and locus of control research.
\end{abstract}

Keywords Theory of mind · Empathy · Spirituality $\cdot$ Religion · Evolution ·

Buddhism · Christianity · Qi · Locus of control · Psychotherapy · Bible ·

Self psychology $\cdot$ Psychology

Theory of Mind (ToM), which has become increasingly prominent in the neurosciences, could be extended into the area of religion and health. It could provide a new perspective on spirituality and might also become the basis for discussing what hundreds of different schools of psychotherapy share in common. In other words, ToM could be a unifying theory.

\section{What Constitutes a Unifying Theory?}

The hallmark of a unifying theory is its ability to explain in one simple model a multitude of seemingly unrelated phenomena. Plate tectonics is an example. As of the mid-twentieth century, we knew about the following apparently unrelated phenomena:

J. H. Boyd (两)

57 Bethany Woods Road, Bethany, CT 06524, USA

e-mail: JeffreyHBoyd@gmail.com 
- the San Francisco earthquake of 1906;

- the shape of the eastern coastline of South America on the map seemed parallel to the shape of the coastline of west Africa;

- we knew of volcanoes; and

- we knew that there were islands in and mountains under the ocean.

None of those four things appeared to be related. Then in the 1960s Harry Hess, Robert Coats, Jason Morgan and Xavier LePichon proposed the theory of plate tectonics. We were astounded to discover that the four totally unrelated phenomena described above were all reflecting the same underlying flow of magma, the way water boiling from the bottom of a pot circles across the surface. However, in the case of magma the convection currents move slower than that of water boiling in a pot, like the speed at which your finger nails grow.

Unrelated phenomena sometimes provoke the mind into some sort of triangulation process from which a unifying theory emerges. ToM has already proved itself to be a unifying theory in a half dozen unrelated fields of research, as we will discuss shortly.

\section{Description of Theory of Mind}

ToM refers to your ability understand that another person has a mind, a way of thinking, feeling, and behaving which may be different than your way of thinking, feeling and behaving. ToM seems so simple that it is hard to believe that it could hold such promise as a multi-disciplinary theory.

\section{Three Examples of ToM}

\section{Example 1}

Driving your car, you notice that the car ahead of you has its right blinker light on. This is a simple illustration of how ToM works. The law requires that a driver who intends to turn right, turn on his or her right blinker light, in order to make other drivers aware of that intention. It is a signal that conveys a ToM. If the car ahead of you does not turn, or abruptly turns left, that could cause an accident, and at a minimum, annoys the other drivers. The words in italics indicate those aspects of the blinking red light that involve a ToM.

Unlike blinker lights, brake lights do not convey a ToM. When the car ahead of you has brake lights on, that means the driver's foot is already on the brake pedal. You may presume that the driver ahead intends to slow down, i.e., you may impute a ToM, but there is no direct communication from that driver's mind to your mind, the way there is when a blinker light is on. The driver ahead might be completely unaware of braking, and may intend momentarily to accelerate.

\section{Example 2}

You observe that a man named John enters a bedroom, turns around and exits. You wonder why John did this (Baron-Cohen 1995, p. 1):

- "Maybe John was looking for something he wanted to find, and he thought it was in the bedroom. ... 
- Maybe John heard something in the bedroom, and wanted to know what had made the noise. ...

- Maybe John forgot where he was going: maybe he really intended to go downstairs."

You automatically assume that John has a mind and that his behavior was purposeful. A ToM is so natural that it is difficult for us to describe events without invoking a ToM. The alternative to having a ToM would be to say:

- John entered the bedroom, turned around and exited: END OF STORY.

Suppose John were a robot. While you might speculate that the robot entered the bedroom for a purpose that would be incorrect thinking. Actually the robot named John entered and exited the bedroom because it was programmed to do so. In order to understand the behavior you need to examine the computer code that controlled it. The code might say that John moves forward until some criterion is met, then makes a $U$ turn and moves forward again. A ToM explanation would not fit, because the robot does not actually have a mind. It is simulated to appear as if it had a mind.

\section{Example 3}

ToM is also illustrated by this vignette:

I make some cookies and bring them to work. I show my coworker, George, that I am putting the cookies in my desk drawer and invite him to help himself anytime. A little later, I notice a couple of ants crawling near my desk and decide to move the cookies to a high shelf. That afternoon, on my way to the mailroom, I see George headed toward my office. I say, 'They're on the shelf.' I have effortlessly computed that George wants a cookie but because he incorrectly believes the cookies are in the drawer, he will fail to find them; if I tell him where 'they' are, I will change his belief, enabling him to fulfill his desire for a cookie. I can explain and predict George's behavior in terms of his mental states, because I have a theory of mind. This sort of reasoning is complex when made explicit, yet we do it all the time, with little or no conscious reflection. Developmental evidence, however, suggests that such thinking is not automatic for young children, who must develop a number of skills in order to reach the adult level of competence in understanding of mental states. (Miller 2006)

ToM is a construct grounded in the neurosciences, especially in functional neuroimaging: electrical probes inside the brains of monkeys, experiments with children and patients with psychopathology, brain damage or dementia. Mirror neurons (described below) are central. ToM is part of a larger field called social intelligence or social cognition (Brothers 1990; Adolphs 2001; Brüne and Brüne-Cohrs 2006).

\section{ToM Has Already Become a Unifying Theory}

Early in the twentieth century there was a quest to discover what caused earthquakes, and an apparently unrelated quest to discover whether the continents were drifting apart. Eventually plate tectonics emerged as the Holy Grail which was being sought by those different lines of research.

Similarly ToM provides or could provide answers to the following unrelated quests:

a. Ethologists have sought to describe the social interactions of humans as parallel to that of other primates such as chimpanzees, baboons, apes, orangutans, lemurs or macaques. 
b. There has been a quest to understand and treat childhood autism.

c. .... A quest to find how the mind relates to the brain.

d. Language pathologists have sought the neurological foundations of language and linguistic deficits.

e. Paleo-anthropologists have a quest for how homo sapien consciousness evolved from that of hominids and our ancestor apes.

At first glance these different quests appear as utterly unrelated to one another as did geological events early in the twentieth century. Only when the same Grail emerges from each of these apparently unrelated quests, does the possibility dawn on us that perhaps all these blind scholars have been groping different aspects of the same one elephant. Indeed, ToM appears to be the Grail which was being sought in all those apparently unrelated quests. This is similar to plate tectonics, and how a multitude of seemingly unrelated phenomena all fit into one simple theory.

ToM Could Be Extended into Spirituality and Psychotherapy

If ToM is that aspect of the primate mind that made some hominids human, then everything about humans is implicated in ToM, including all of psychology and spirituality. That is the short version of this article's core message. ToM can be applied to all the intellectual territory that is of interest to the Journal of Religion and Health.

Consider the following two questions:

- If your ToM appreciates that I have a unique way of thinking and feeling, does your ToM appreciate the transference and counter-transference issues, because I also have thoughts and feelings about you, which are colored by the dreams I had last night and by my early life experiences, the history of our relationship, and by my culture? The interactive dance of two ToMs has its own dynamic. How do you feel about my feelings about your feelings about me?

- When you and I ponder each other's ToM, are we also aware of a transcendent ToM, God's ToM, God's way of thinking and feeling, a spiritual perspective that sheds a different light on what both of us think and feel?

These two questions will be explored in the second half of this article. They open new vistas for the study of ToM, a potential bonanza for $\mathrm{PhD}$ theses in mental health and spirituality. Previous research in the neurosciences has investigated simple questions like: what is the difference between a child who has ToM and one who lacks ToM. Which neurons in the primate brain lay the foundation for ToM? Are children with autism incapable of having a ToM?

We are proposing that ToM research could be cantilevered out into realms that are much more complex than the questions mentioned in the previous paragraph. However, before we can propose our hypothetical ideas, we need to start by reviewing what previous research has established.

\section{Brief Review of Previous Research on ToM}

In an article like this, aimed primarily at extending ToM into the arenas of spirituality and psychotherapy, we cannot do justice to the vast amount of research that has accumulated on ToM over the last three decades. We can use a broad brush to sketch a panorama of the 
neurosciences, the purpose of which will be to serve as a backdrop for our comments about spirituality and psychotherapy. For more thorough reviews, the reader is referred to the articles by Brüne and Brüne-Cohrs (2006) and by Oberman and Ramachandran (2007).

The term Theory of Mind was first coined in 1978 by David Premack and Guy Woodruff at the University of Pennsylvania as a way of describing how chimpanzees infer the mental state of their fellow chimpanzees. They wrote, "An individual has a Theory of Mind if he/she imputes mental states to himself/herself and others." Although the concept of ToM caught on, the original observation that chimpanzees might be capable of ToM remains controversial. Other ethologists studying baboons say they doubt that non-human primates are capable of ToM (Cheney and Seyfarth 2007; Wade 2007).

After Premack and Woodruff introduced the term, ToM was picked up by psychologists studying early child development, because at around the age of four a child discovers that consciousness is local. Prior to that, children believe that everyone knows what the child thinks and feels. At age of four the child tells his or her first lie, and discovers that the parents don't automatically know that it is a lie. This deception is the discovery of ToM. The boundary between the presence or absence of a ToM could be defined as when a child begins to think, "I know something that you don't know." Following that comes a growing awareness among children that, "I understand what you are thinking, which is different from what I'm thinking." Before age four children are incapable of such ideas.

The preceding paragraph illustrates what we mean when we say that ToM research heretofore has been focused on simple questions such as "What is the difference between a child who has ToM and one who lacks ToM."

\section{Autism and the Autism Spectrum}

Child psychologists realized that the absence of ToM could be the core deficit in autism. What is autism? Two illustrations of what constitutes autism (given in the next two paragraphs) convey a sense of what constitutes the disorder.

Kanner (1943), who first described autism, gave many illustrations of which this was one: an autistic boy would walk on a crowded beach "straight toward his goal irrespective of whether this involved walking over newspapers, hands, feet, or torsos, much to the discomfiture of their owners. His mother was careful to point out that he did not intentionally deviate from his course in order to walk on others, but neither did he make the slightest attempt to avoid them. It was as if he did not distinguish people from things, or at least did not concern himself about the distinction."

Another boy with autism is described as follows: "He never really seemed to look at anyone directly. Rather, he would look at them only fleetingly or else not at all. Despite this, John seemed to notice everything in minute detail. He could ride his bicycle along the most crowded pavements without knocking anyone over .... He would also do things his parents found embarrassing, like grabbing and eating sandwiches from a stranger's plate in restaurants" (Baron-Cohen and Bolton 1993).

The two boys just cited did not draw a distinction between people and other objects. They did not comprehend that people had minds and feelings. There is a growing consensus that the core cognitive deficit in autism is the absence of a ToM (Baron-Cohen 1995; Baron-Cohen et al. 1997). The absence of a ToM may "underlie the social, communicative, and imaginative abnormalities that are diagnostic" of autism (Baron-Cohen et al. 1997). Whether such children have a neurological deficit of mirror neurons (described below) is unknown. 
There is a spectrum of developmental disorders that are related to autism, but less severe. For example, clients with Asperger's Syndrome have peculiar ways of relating to other people. They lack empathy, appearing aloof, condescending, and contemptuous. They might be brilliant in non-social arenas, such as having extraordinary skills with computers, or excelling in science and math. However, when it comes to people and feelings, they simply don't get it. Some of the geeks and nerds who are technological whizzes, are socially inept because of Asperger's Syndrome. These people are also thought to have deficits in terms of ToM (Baron-Cohen et al. 1997; Baron-Cohen et al. 2001; Buitelaar et al. 1999; Oberman and Ramachandran 2007; Brüne and Brüne-Cohrs 2006).

Many schizophrenic patients have suffered from autism or Asperger's at an early age. The onset of schizophrenia makes their ability to understand other people worse. If a schizophrenic client experiences family members as being replaced by aliens who look exactly like the original family members, that tells you that the schizophrenic client can no longer understand how the family members think. There is a failure of ToM. ToM deficit in schizophrenia is also a focus of intense research (Brüne 2005; Savina and Beninger 2007).

\section{"Monkey See, Monkey Do"}

Ethics allow us to poke electrical probes into the brains of monkeys, but not into the brains of humans. Therefore, many studies are done on monkeys, which inspire comparable studies of the human brain using functional brain imaging, or other techniques that don't involve electrical wires inserted into human brain neurons.

Probes in the brains of monkeys show that there are something called mirror neurons, which fire when the monkey observes someone else's hand movement, and the same neuron fires when the monkey moves its own hand in that particular pattern. This mirror neuron is also found in humans, and is thought to be one of the foundations for mimicry (Brüne and Brüne-Cohrs 2006). In other words, mirror neurons provide a brain mechanism for the popular saying, "Monkey see, monkey do." This is usually said of children. Embedded in that saying is the recognition that monkeys and children are similar in terms of the ease with which they imitate. This is consistent with both species having mirror neurons. That, in turn, has implications for our theory of how humans and monkeys evolved from a common ancestor.

One can imagine a series of small steps. First is the observation that "I can copy what you do because the same mirror neurons fire in my brain when I do what I saw you do." The second step is, "I can simulate your behavior, even without your doing it, because I know how I would do it." The third step would be, "I know what you are about to do, because if I were doing what you do, then the next thing I would do would be X." The fourth step would be, "I can infer your intention, because if I were doing what you are doing, then my goal would be X.” By this fourth step we are immersed in a ToM, because we are inferring and imputing intentions, motives, and mental states in the other person. It is possible that the evolution of our ancestors from homo erectus to homo sapiens involved an evolution of the brain so that it was capable of the logical steps described in this paragraph.

Mirror neurons are one of the neurological foundations for a ToM. Based on this type of reasoning, there is a vast amount of research being conducted using functional brain imaging, and an intense dialogue between researchers studying the human brain and those studying the monkey brain (Brüne and Brüne-Cohrs 2006; Moriguchi et al. 2006). We would like to be able to test the brains of other hominids, but no other hominids than ourselves are currently alive. 
There is also an intense discussion underway seeking to understand how many of the steps of the previous paragraph are monkeys capable of, versus how many of these steps are young children capable of. Likewise, there is discussion of how did our ancestor hominids develop these steps that led to the capacity for ToM. Was ToM a necessary step in the development of language, or was language necessary to develop ToM during the course of evolution? After all, how can you impute goals and purpose to someone else, unless you are able to put that into words (Miller 2006)?

Mirror neurons are particularly dense in Broca's area of the brain, which is where the articulation and pronunciation of words is located. When a parent teaches a baby how to say a word, like "ma-ma," the parent carefully mouths the word, with exaggerated lip and tongue movements. This behavior is soaked up by the mirror neurons in the child's Broca's area, so that the child eventually learns to mimic the lip and tongue movements. Language is not abstract, it is rooted in the tongue, and in that part of the brain which controls the tongue. Thus, according to ToM theory, language arises first and foremost because of mirror neurons in the Broca's area of the human brain. The geography of language in the human brain is not limited to Broca's area. For example, there is also Wernicke's area which assembles sentences in a coherent order. ToM hints that perhaps Broca's area is older than Wernicke's, that it evolved first as our ancestor hominids began to make meaningful grunts, then evolved brains capable of understanding what those grunts must mean about how the other person was thinking (Oberman and Ramachandran 2007; Miller 2006).

Mirror neurons also lay the foundation for our social skills. More than 200 years ago Smith (1759) described how our perception of other people involves sensations in our own body. Smith wrote, "When we see a stoke aimed, and just ready to fall upon the leg or arm of another person, we naturally shrink and draw back on our leg or our own arm .... The mob, when they are gazing at a dancer on the slack rope, naturally writhe and twist and balance their own bodies, as they see him do."

We now know that mirror neurons in the brain mediate the phenomenon which Smith described. The ability to understand someone who is about to be clobbered, or who is walking a rope, we must experience the other person as being "like me" (Meltzoff and Moore 1995) and we mimic inside ourselves what it would be like to be in that other person's position (Oberman and Ramachandran 2007). All this is done automatically; it is so natural to us that we're not even aware that we are doing it. Imitation and mimicry are essential to our understanding of other people, which funnels through the mirror neurons. By experiencing how we would feel under similar circumstances, we can appreciate how the other person must be feeling. As we simulate the other person, experiencing inside ourselves what we would be thinking, feeling and intending to do if we were in that other person's shoes and seeing the world through that other person's eyes, we automatically experience a theory of the other person having a mind.

In this brief review of previous research on ToM, we have only scratched the surface. Research on this subject is vast and fascinating. Other aspects of the published research can be found in Daniel Drubach's article elsewhere in this issue of the Journal.

\section{ToM Provides a New Perspective on Spirituality}

The idea of extending ToM from the neurosciences where it originated into the study of spirituality and psychotherapy may seem odd. That is not the roots of ToM, nor is it where research has previously blossomed. However, ToM is a robust and fertile theory. Like the 
theory of plate tectonics, we are repeatedly amazed to discover new applications. For example, after plate tectonics was established as a construct, it was extended to the theory of a hot spot in the earth's core that gave rise to the Hawaiian ridge of islands as the Pacific floor moved northwest. Like the theory of hot spots, we are proposing to extend the Theory of Mind into a new area, the way plate tectonics was extended to explain the Hawaiian Islands and the Emperor Seamount Chain of mountains arising from a hypothetical hot spot (see the map of the Pacific Ocean floor at http://pubs.usgs.gov/gip/dynamic/Hawaiian.html).

Since ToM describes a fundamental capacity of the human mind, that which made some hominids into humans, it is not surprising that all homo sapien activities can be illuminated by ToM. What this article offers are new applications of ToM as a lamp to illuminate spirituality and psychotherapy.

Drubach (2008) was the first to propose that ToM could be extended from the neurosciences into religion. He is a Jewish behavioral neurologist at the Mayo Clinic, working with patients with fronto-temporal dementia. As their brains atrophy, these patients lose their capacity for empathy. He writes, "Previously loving fathers and husbands become oblivious to the emotions exhibited by members of their family. The patients are described as insensitive and uncaring, which can be especially upsetting to young family members." It is easy to see how this clinical work opened the door for neurologists to study the loss of ToM as central dimension of the clinical picture of fronto-temporal dementia.

As an observant Jew, Drubach also began to experience that ToM shed light on his religious experience. He writes, "A prominent theme in Jewish mystical literature is that of God's empathy for human's emotional status, be it joy or suffering." Drubach introduced the idea that God has a Theory of Mind, that God not only understands us (as do members of our own species) but also understands us perfectly. ToM is also the core experience of Passover: "One must not merely understand and remember, but in fact relive, putting ourselves in the shoes of those who participated in the Exodus from Egypt."

We know that Drubach was the first author to apply ToM to religion and spirituality because we searched the religious and medical literature. In February 2008 we entered the term "theory of mind" into the website of the Religious and Theological Abstracts (http://rtabstracts.org/search) and found zero abstracts on that subject. We then searched the Medline database by using the OvidSP website (http://ovidsp.tx.ovid.com/spb/ovidweb.cgi), and searched for articles containing the term "theory of mind," cross referenced with either the terms "spirituality" or "religion." There were no articles with that combination of search terms. Daniel Drubach's article was written before the article you are now reading.

Following Drubach's lead, we propose to demonstrate how ToM plays a central role in Christianity, Buddhism, and other forms of spirituality.

\section{ToM, the Bible and Christianity}

The Bible is chock-a-block full of Theory of Mind. Consider Jacob's ToM as he crosses the Jabbok brook (Genesis 32:3-33:17), about to meet Esau for the first time in decades. Jacob has a false belief about Esau's mind, convinced that Esau intends to kill him because he had stolen Esau's blessing when Isaac was dying. Esau approaches with an army of 400 men. False beliefs about how someone else like Esau is thinking, are central to ToM. Expecting the worst, Jacob divides his people into different parties, as a way of assessing Esau's viewpoint. If Esau kills Leah and the first party, it will confirm Jacob's worst fears, and perhaps Jacob and Rachel will manage to escape. In the end Jacob learns that his ToM was erroneous: Esau is forgiving and gracious. Implied, but not stated in this story, is a 
ToM about God, namely that the Lord has dealt abundantly with both Jacob and Esau, so that sibling rivalry is overwhelmed by God's generosity over the intervening decades. Both patriarchs had been blessed by God since Isaac's death.

After Jacob's death, one of the most compelling Theory of Mind stories is found in Genesis 50:15-21. Joseph's brothers have a false ToM about Joseph, expecting that he will enslave or kill them because they had sold Joseph into slavery as a teenager. "But Joseph said to them, 'Do not fear, for am I in the place of God? As for you, you meant evil against me, but God meant it for good, to bring it about that many people should be kept alive, as they are today. So do not fear; I will provide for you and your little ones.'” In this passage the word meant refers to a ToM, namely an understanding of what someone else intended or wanted. Joseph has a much more sophisticated ToM than his brothers. His view is that although they were motivated by evil, nevertheless God's mind was motivated by generosity. Furthermore, Joseph believed that God was able to accomplish his purposes through the evil of Joseph's brothers. This ToM, namely that God's mind is capable of accomplishing something good through the evil of human minds, became pivotal in Jewish, Christian and Islamic understanding how God brings good out of evil. The idea is mentioned by Paul (Romans 8:28): "We know that for those who love God all things work together for good." It shows up again in Augustine of Hippo, who explained the existence of evil as follows: "God judged it better to bring good out of evil than not to permit any evil to exist" (Augustine 1955). This is a Theory of God's Mind. One could view the Bible and Christianity as being primarily a Theory of God's Mind.

Jesus was a master of using ToM, as evident in his parables. Consider this parable: "The kingdom of heaven is like treasure hidden in a field, which a man found and covered up. Then in his joy he goes and sells all that he has and buys that field" (Matthew 13:44). The man knows how other people think, namely, "That is just an ordinary field." Others do not know about the buried treasure. Deception and false beliefs play a prominent role in ToM. The words, "The kingdom of heaven is like," imply another ToM, namely that Jesus knows how his audience thinks. He knows we would like to win the lottery, and we would be willing to deceive other people to do so. By analogy, Jesus teaches that we should desire the kingdom of heaven as much as we want to win the lottery, even though other people don't view that kingdom as worth much.

ToM is pivotal in Jesus' parables. Consider the rich fool, Luke 12:15-21:

And he said to them, "Take care, and be on your guard against all covetousness, for one's life does not consist in the abundance of his possessions." And he told them a parable, saying, "The land of a rich man produced plentifully, and he thought to himself, 'What shall I do, for I have nowhere to store my crops?' And he said, 'I will do this: I will tear down my barns and build larger ones, and there I will store all my grain and my goods. And I will say to my soul, Soul, you have ample goods laid up for many years; relax, eat, drink, be merry.' But God said to him, 'Fool! This night your soul is required of you, and the things you have prepared, whose will they be?' So is the one who lays up treasure for himself and is not rich toward God."

The parable consists of a description of an error in the farmer's thinking (i.e. ToM). The farmer falsely believes he has plenty of time. The parable then introduces Theory of God's Mind. God thinks differently: the farmer will die tonight.

The juxtaposition of human versus God's ToM is a defining characteristic of Jesus' parables. For example, Jesus spoke of people having eyes but not seeing, and ears but not hearing (Matthew 13:13-15; Mark 8:18). His point was that they did not see things 
the way God sees them, nor hear things the way God hears them, i.e., they did not understand God's mind.

Christian theologians describe the Bible as God's self-revelation. This is what we are calling Theory of God's Mind. Enfolded within that self-revelation are three experiences:

(a) that God has a perfect ToM vis-à-vis all humans;

(b) humans can only partially know God's way of thinking; and

(c) knowledge of God depends on God's self disclosure.

ToM and Buddhism

Siddhartha Gautama was a prince in Kapilavastu, Nepal. Due to a prophecy about the boy, his father, King Suddhodana arranged for Siddhartha to be shielded from the misery of life. At the age of twenty nine the crown prince was out on a carriage ride when he saw an old man. That jolted Siddhartha's ToM. Until then his ToM was, "Everyone is as happy as I am." By meeting an old man, Siddhartha's ToM expanded to include the possibility of suffering. The next day Siddhartha met someone with a disease. Subjected to a spiritual earthquake measuring ten on the Richter scale, Siddhartha's ToM fractured and began to collapse. The next day he saw a corpse, i.e., a person whose mind was permanently absent. Finally he met an ascetic, whose experience of life was deprivation. His ToM shattered and in ruins, Siddhartha left the palace to attempt to construct a new perspective. Six years later, meditating under a Bodhi tree, he attained Enlightenment. Thus Buddhism was born as an alternative to ToM.

We will compare Buddhism to Christianity in order to demonstrate a difference between the two religions vis-à-vis ToM. There are two ways of saying the same thing. A Buddhist might say that you should deal with suffering by detachment. A Christian might say you should turn your sorrow over to God, place your burden at the foot of the cross. Both vocabularies involve alleviation of spiritual pain by detachment. The difference is that the Buddhist approach is more impersonal, in the sense that it does not involve another Person with a mind and a heart, namely God.

A crisis occurs when a person says, "I can't stand it anymore." Buddhism offers to resolve that crisis by saying, "Detach, let go!" whereas Christianity offers to resolve it by saying, "Let God worry about it." The Buddhist approach does not involve ToM, whereas the Christian approach involves ToM, namely a theory of God's mind. Death illustrates this difference. A Christian might look forward to going to Heaven after death, where she or he could be closer to God, knowing God on a personal level. A Buddhist might say he/ she would like to go to Heaven in order to rescue Christians, teaching them that they shouldn't want to be there.

The top priority for Christians is God, who is conceived of as a Person. The top priority for Buddhists is Nirvana, which is impersonal. One image that is used to describe what it would be like to experience Heaven is that it would be like an iron poker in a fire, infused with warmth from the Spirit, but still preserving its individual shape and integrity. Thus as a Christian gets closer to God the Christian continues to have a mind, integrity and individual identity. Even in Heaven ToM is preserved: you have a mind, God has a mind, you have a theory about God's mind and God has a theory about your mind. A different image is used to describe what it would be like for a Buddhist to enter Nirvana. It would be like a drop of water merging into the ocean, losing all its individual identity. There is no ToM immersed in the sea. ToM is dissolved the way sugar disappears into a cup of tea. 
This illustrates what we mean when we say that Christianity preserves our human ToM by worshiping a God who also has a mind and a Theory of Mind; whereas Buddhism solves the problem of suffering by dissolving ToM into an impersonal spirituality.

Your ToM is maya, an illusion. Maya is a Sanskrit word meaning that which we view as "reality" is actually smoke screens and mirrors, a false appearance of reality. Your sense of being a person, having a self (or soul) is an illusion. The Buddha taught that there is no such person, no "self," no "soul." The person you believe yourself to be, is a fiction of your own imagination. This is the Buddhist doctrine of anatman, where an means "no such thing," and atman refers to the self or soul. Just as you are not a person, likewise, no other people exist either. Thus the concept of ToM dissolves, falls into a black hole, because of there are no humans to participate in ToM. Impersonal forces prevail, whether we call those forces anatman, maya, detachment, or Nirvana.

When Siddhartha Gautama attained Enlightenment under the Bodhi tree, he did not discover a Theory of God's Mind. His Enlightenment consisted of discovering the Middle Way, which involved the Four Noble Truths, Eightfold Path, Dharma, and Sangha. The ultimate energy of the universe in Buddhism is sometimes called sacred emptiness. It is better known as Nirvana. We cannot develop a Theory of Mind about sacred emptiness, nor about Nirvana, because we are not relating to a Person. Thus we might say that the Buddha taught a way to escape from the suffering that comes from a Theory of Mind, but we would not say that he taught that there is a greater mind than ours, to which we can relate the way Jews, Christians and Moslems relate to God as a Person.

God (or Allah) has a Theory of Mind about us, according to the Jews, Christians and Moslems. Nirvana does not have a Theory of Mind about us.

\section{How ToM Divides Two Varieties of Spirituality}

There is a continental divide that appears to distinguish biblical and Asian religions. The three biblical religions (Judaism, Christianity, and Islam) are based on ToM, because God or Allah has a personality. Each of these religions consists of a Theory of God's Mind. That is the core of what these religions are about. Theory of God's Mind is the defining feature of these three religions.

It is, for example, the central message of the Koran. Moslems have affection and feelings about Allah on a personal level, because they think of Allah as a Person, with a mind, feelings, and purpose. Allah may be so noble that we hesitate before even presuming that we could have thoughts and feelings about Allah, but Islam preserves ToM by saying that Allah is a Person.

This is not true of Asian spirituality, or at least, Asian spirituality as it is often taught in the United States by people like Joseph Campbell and Alternative Medicine gurus. In Buddhism, Taoism, Shintoism, and in the Analects of Confucius, the ultimate spiritual energy is experienced as impersonal.

Take qi (pronounced "chi”) for example, a Chinese medical term referring to the life force. A similar idea is found in both Chinese and Indian medicine. India has a medical tradition called Ayurveda, focused on the flow of energy (called prana) through the body, particularly through chakras where this energy is especially concentrated in the spine. This life force (called $q i$ in China or prana in India) is an impersonal energy that animates the human being. Healing is focused on the flow of this energy. Qi flows through us like a magnetic field, and provides the life-force of everything. Acupuncture and Reiki are examples of therapies based on this spiritual energy. By inserting needles into the skin we 
influence how qi flows through the invisible meridian channels of the skin, which directly influences how qi circulates through the inner organs. This results in healing by restoring balance to the organism.

$Q i$ is a concept for which we have no Theory of Mind. We cannot relate to $q i$ by thinking and feeling that it is like us. Therefore, we use impersonal pronouns such as "it" when referring to $q i$, whereas we use personal pronouns such as "He" or "She" when referring to God if we are Jewish, Christian or Moslem.

Although Joseph Campbell and other experts on world religions say that Asian religions do not have a personal god but the three biblical religions focus on a personal God (or Allah), we will show below that is an over simplified view. Both personal and impersonal forms of spirituality are found everywhere, we propose.

\section{Why Religion/Spirituality Arose in Evolutionary Perspective}

It is easy to see how the hominids that evolved to have ToM, language, culture and social organization would be more likely to survive by developing new food sources and ways to contend with predators and would begin to flourish as a species. Those hominids became the homo sapiens.

Once our species was self aware, so that most of us understand that other people have minds and self-awareness, there are anxieties that come with that consciousness. We become aware of death, suffering, finitude, and the apparent futility of existence. We are also awestruck with the magnificence of the world, the cornucopia of life, and we yearn to give thanks for being alive. However, to whom or to what do we give thanks?

Archeologists tell us that among the hundreds of excavation sites where they have explored early human settlements, long before there were any written languages, long before the Bible, Upanishads or Buddha, before there were cities, there was usually evidence of religion or spirituality (Collins 2003). The ubiquity of spirituality, long before written language, was true all over the earth, at excavation sites such as Olduvai Gorge, Zhoukoudian, Bilzingsleben, Borum Eshøj, La Ferrassie, Mözs, Klasies River Mouth, Bǒgazköy, Ajanta, Chichèn Itzá, Çatal Hüyük, Pompeii, Snaketown, Broken K Pueblo, Koonalda Cave, Mounte Verde, Roonka Flat, Tell es-Sawwan, Stonehenge, Tiszapolgá, Köln-Müngersdorf, Ozette and hundreds of other excavation sites (Collins 2003).

How do we account for this ubiquitous evidence of spirituality from long before humans recorded any history, among tribes scattered all over the earth with no knowledge or communication with one another? This article proposes that spirituality arose because ToM brings with it existential problems that can only be solved spiritually. Another way to say it would be that the Spirit made man/woman in his/her/its own image (Genesis 1:27).

"For at least the last 35,000 years, ritual and religion have been a universal feature of human society .... It is difficult to say what beliefs were held by these early human communities ... people were prepared to devote considerable time and energy to the creation of works of ritual or religious significance. This basic human impulse can be traced throughout the archaeological record down to recent times in temples, tombs and iconography. This record of ritual and religion can be divided into two parts: the remains of the special structures constructed for religious purposes; and the surviving traces of the ritual activities themselves, in the form of offerings, sacrifices and cult objects" (Collins 2003, p. 48).

Sometimes, as in Stonehenge, humans were looking to the sky for their gods (or Astrological guidance). Sometimes they were looking down toward the earth in their religious practices, or building elaborate tombs with burial rituals (Collins 2003). The 
concept of an atheistic or non-spiritual approach to life does not seem to have occurred to our ancestors.

\section{Personal versus Impersonal Spirituality}

We said above that there are two different kinds of spiritual solutions that can be found to the existential problems of ToM: one solution is to say that our fragile ToM is grounded in the mega-ToM of a parental god upon whom we can depend; the other solution is to say that our fragile ToM is grounded in an impersonal energy such as qi, prana, sacred emptiness or Nirvana, so that we can relax about death, suffering and finitude.

One of the two forms of spirituality is based on the Theory of God's Mind, the other is based on impersonal energy to which we cannot relate using ToM.

Both forms of spirituality recognize that there is a problem with ToM. Since humans are finite and fallen, therefore ToM involves claustrophobia and spiritual suffocation. The human mind for example appears to come to an end at death, resulting in a spiritual urgency about ToM when someone we love dies. The three biblical religions solve that problem by saying that our ToM is merely a chip off a larger block, that we are children of God. God has a mind also, He/She is like us, or vice versa. Prior to the Bible, people in Egypt, Babylon and throughout the Middle East already took a personal approach to spirituality, based on ToM. By this we mean that they served gods who had minds and personalities (such as Ashtoreth the goddess of fertility, Molech, Isis or Baal). Pharaoh claimed to be a god, and had a mind. People in the ancient Middle East worshipped their ancestors, which is also a personal approach to spirituality. About the only example of impersonal spirituality that we find in the ancient Middle East is Astrology in ancient Babylon and Egypt.

Asian spirituality solves the existential problem of ToM by saying that ToM is not all there is to life, there is a life-force ( $q i$ or prana), an impersonal energy which is the ultimate force, and which allows us to relax about death, life and ToM. These impersonal spiritualities dissolve ToM the way sugar disappears into a cup of tea.

Yet this portrayal of spirituality is overly simplistic. It is inaccurate to say that the two approaches to spirituality (personal versus impersonal) are located in the three Biblical religions versus Asian religions. We propose that these are two sides of spirituality everywhere.

For example, impersonal spirituality can be found in Christianity in the form of ideas about Providence, which is the Christian name for what other people call "fate." Shakespeare wrote, "There's a divinity that shapes our ends, rough-hew them as we will" (Hamlet V, 2, 10). One cannot relate to Providence using ToM in any direct way.

This is not the only impersonal form of spirituality found in Christianity. The Bible speaks about walking on the right path (Psalm 1), and about acquiring wisdom (Proverbs), which are impersonal approaches to spirituality. To walk on the right path may be important, but it is not something that fits immediately into a Theory of Mind. Similarly ethical and moral laws, such as the Ten Commandments, are spiritual principles to which ToM cannot easily be applied.

Similarly Buddhism cannot be portrayed as a purely impersonal religion. In many places the Buddha is worshipped and prayed to as a god. Thus Buddhism also can be a slippery slope skidding back into a ToM. Someone praying to Buddha might think, "The compassionate Buddha knows what I am going through, and urges me to practice detachment." Here the person relates to a theory of the Buddha's mind. That variety of 
Buddhism preserves ToM and thus we would classify it as a "personal form of spirituality."

In order to orient the reader, let's reiterate where we are at this point. We claim that there are two kinds of spirituality, one of which endorses ToM by proposing that the ultimate energy of the universe has a personality, the other of which dissolves ToM into an impersonal energy field. Both aspects of spirituality are found in every religion, including in New Age spirituality, we claim.

Consider astrology. At first we tend to think of astrology as an impersonal spirituality. The locus of control for your life is external to yourself. The only chance you have of influencing your fate today is to understand what the stars and planets have determined to be the possibilities, which you can read about daily in most newspapers in the United States. That sounds completely impersonal. However, there are also the signs of the Zodiac, which slide us into a Theory of Mind. Anyone who was born on November 13 was born under the sign of the scorpion and has a scorpion-like quality of his/her personality. We need to have twelve different theories of mind, depending on when people were born. The mind for someone who is a Scorpio is different than someone who is Taurus, Leo or Sagittarius. Thus we cannot completely separate impersonal spirituality from ToM, even in astrology, which at first appears to be impersonal. So astrology illustrates our claim that both personal and impersonal forms of spirituality can be found in every religious practice.

In the next paragraph we will take this argument to the next step.

We can classify various spiritualities according to whether they are predominantly personal or impersonal. Among the personal spiritualities would be Judaism, Christianity, Islam, ancestor worship, séances with ghosts of the dead, and any religion focused on any god, such as most forms of Hinduism and most of the gods of ancient Egypt and Babylon. Among the impersonal spiritualities would be karma, Buddhism, qi, Reiki, acupuncture, Taoism, reading tea leaves, Ouija boards, tarot cards, palm reading, astrology, the Gaia hypothesis, "the Force" from the Star War movies, communism, Plato's "Forms," Aristotle's "Unmoved Mover," transpersonal psychology, and Andrew Cohen's "Evolutionary Enlightenment" as evident in the next paragraph (Cohen 2008a).

Cohen writes:

Every aspect of the human experience is a completely impersonal affair .... The personal sphere, the personal narcissistic self-sense that is ego, is created moment by moment through compulsive and mechanical personalization of almost every thought, feeling, and experience we have. ... [For example,] when we experience sexual feelings, the feeling of lust is exactly the same for each and every one of us. There may be different degrees of intensity, but the fundamental feeling of that experience is one and the same for all.... The shocking truth is that the whole human experiences is an impersonal event. If you look in your own experience, that's what you'll find. You will begin to see your own personal human experience as an impersonal expression of something that is universal. (Cohen 2003, 2008b)

In summary, ToM sheds light on spirituality, helping us to discern:

- that there are personal forms of spirituality that relate to a theory of God's mind (ToM writ large) and impersonal forms of spirituality that don't involve ToM in any obvious manner.

- ToM also leads us to speculate about existential angst among our ancestors. Once hominids had evolved mirror neurons and ToM, that led to spiritual behaviors involving religious rituals, rites, shamans and priests (Collins 2003). 
How Religion Relates to Health, Using ToM

Our proposal is that ToM produces an existential dysphoria which is amenable to spiritual solutions. Anxiety can arise in a species that is self conscious and aware of war, injustice, exploitation, slavery, rape, child abuse, disease and death. Such anxiety has a negative effect on health. Chronic exposure to stress hormones, for example, are deleterious to health.

Religion and spirituality can produce a sense of wellbeing (Koenig, McCullough and Larson 2001, pp. 97-117). Disease prevention and health promotion usually involves a spiritual dimension, because this is the only way to solve the dysphoria that comes from ToM.

Our purpose in this section of the article is not to provide a definitive discussion of how ToM illuminates the relationship between religion and health, for that would take a book. Our purpose has been to sketch out some possibilities, in the hopes of inspiring other scholars to conduct research on this subject.

Spirituality research suffers from inadequate research tools to define and measure what "spirituality" means. The first step in developing reliable spirituality questionnaires is to define the fundamental difference between personal and impersonal forms of spirituality, because the way you would measure personal religion is different than how you would measure and classify impersonal religion. ToM could provide a basis for the development of more reliable research technology.

\section{ToM as a Lingua Franca for 200 Different Schools of Psychotherapy}

Earlier we suggested that ToM might provide the basis for integrating many schools of psychotherapy, such as depth psychology, self psychology, object relations theory, cognitive therapy, etc. We will now shift gears, leaving spirituality behind temporarily, and focus on ToM and the mental health field.

\section{ToM in Psychotherapy Training}

Consider how ToM is central throughout mental health training. ToM is taught by means of case conferences, which are widely used in the mental health field. A case conference examines the peculiarities of consciousness found in the client, and how the client's mind morphs and evolves over the course of treatment.

The training of psychotherapists commonly involves process notes or videotaping the session. The goal of such training, focusing on the interaction of the student therapist and client, is to help the therapist increase her or his ToM capacity. The supervisor might say, "You aren't listening to what the client is saying," or "You have an instinctive empathy," or, "The client habitually thinks of her/his problems in this way, but if you teach her/him a different approach then her/his problems might be solvable."

A capacity for empathy is partly innate, but not all psychotherapy students have it. Empathic capability can be trained and fine tuned by supervision. Teaching psychotherapy skills means teaching ToM.

\section{ToM and Self Psychology}

We also propose that ToM provides a vocabulary and research tools for investigating and comparing different schools of psychotherapy. 
In order to illustrate how this might be possible, let's consider the example of Self Psychology as taught by Heinz Kohut (Boyd 2000; Kohut 1971, 1984, 1985, 1990; Wolf 1988). Kohut was a Freudian psychoanalyst in Chicago. In the last decade of his life, when he knew he was dying of leukemia, Kohut (1913-1981) taught a new approach to the treatment of narcissistic patients. Such patients, ambitious and sometimes ruthless, become presidents of banks, President of the United States, distinguished professors, entrepreneurs, or occupy prestigious positions. They acquire power, prestige and fame to bolster their self esteem, because that is wobbly without admiration and respect from others.

Kohut had two central concepts: the self and the selfobject. We will discuss them in order: first the self, which refers to the whole person. Kohut had a paradoxical idea. The patient's outward appearance of being high and mighty is counterbalanced by an inward experience of being threatened with obliteration. While Freud said castration anxiety was the worst fear, Kohut said the worst fear was that of disintegration. Normally the narcissistic person can function because he or she has surrounded himself/herself with people who applaud him/her or are intimidated by him/her. Being worshipped by others, or having power over others, supports the patient's self-esteem. The narcissist doesn't feel OK unless valued by others. The crisis comes when the narcissistic person loses her/his job as CEO, or is divorced by her/his spouse. Robbed of external supports and approbation the client begins to crumble and implode, which is evident because the client is more contemptuous than usual, belittling other people more aggressively.

The second of two terms that are central in Self Psychology is the word selfobject. Everyone other than Kohut thought the word selfobject was a terrible term, because it sounded as if it were referring to an object. However, that is not what the word selfobject means. Rather it is an experience, namely any experience which provides the psychological nourishment necessary to support the self and allow it to grow stronger. The vast majority of selfobjects involve an experience of empathy. When the client feels heard and understood he or she feels better and can begin to heal. The client finds it therapeutic simply to be listened to with empathy, even if the therapist can offer no suggestions or solution to the client's dilemma. An experience is not a selfobject simply because it makes you feel good; it must be an experience which performs an essential psychological function. As oxygen is necessary for growth, so a selfobject is essential to the self.

Not all selfobjects involve empathy. Kohut said that creativity and music can help you pull yourself together, allowing healing. However, most selfobjects are experiences of empathy, i.e., having someone else see the world through your eyes and walk in your shoes. In Self Psychology this is called empathic attunement. When a guitar is played, the strings of another guitar in the same room vibrate at the same wavelength, because of attunement.

Empathy is a core feature of ToM. To have someone else listen and comprehend what you feel like, how bewildered and beleaguered you are inside, how incoherent, chaotic life is for you, that is what makes psychoanalysis therapeutic according to Kohut. This is the selfobject experience. The reason the narcissistic patient did not have a more healthy self to begin with was because her/his parents didn't understand who she/he was as a child. Psychotherapy is a corrective emotional experience. It is a healing relationship.

ToM and Self Psychology both focus on the experience of one person getting in sync or harmony with another person, so that the therapist knows the mind of the client as well as the client does, or perhaps better. Thus ToM is capable of providing a vocabulary for discussing Kohut's concept of the selfobject, which is one of the two pivotal ideas in Self Psychology. 
There are two hundred other schools of psychotherapy. We invite other writers to demonstrate that ToM can provide a vocabulary for illuminating the other 199 schools.

ToM and Homo Psychologicus

ToM is what makes our species Homo psychologicus (Humphrey 1984, p. 3). As Humphrey says, "Human beings are born psychologists." "Whatever may be the logical problems of describing inner experience, human beings everywhere openly attempt it. There is, so far as I know, no language in the world which does not have what is deemed to be an appropriate vocabulary for talking about the objects of reflexive consciousness, and there are no people in the world who do not quickly learn to make free use of this vocabulary. Indeed, far from being something which baffles human understanding, the open discussion of one's inner experience is literally child's play to a human being .... This common-sense vocabulary is acquired so easily suggests that this form of description is natural to human beings precisely because it maps directly onto an inner reality which each individual, of himself, innately knows.” (Humphrey 1984, pp. 5, 8)

\section{Applications of ToM to Other Well-Known Subjects}

ToM provides a new vocabulary and new research techniques for investigating old and familiar issues in spirituality and psychotherapy. A new vocabulary has the advantage of casting things in a new light, so that what we thought we knew is seen afresh, and other things we never thought about are visible. When we apply a ToM perspective, psychology and spirituality appear more closely related than most scholars would anticipate.

An example would be psychological research on locus of control and self-efficacy (Rotter 1954, 1966, 1975; Bandura 1991, 1994). Before we explain how ToM can be applied to this field of psychology, we need to provide a thumbnail sketch of locus of control.

Some people experience life as something over which they have influence and control (internal locus of control), whereas other people experience themselves as if they were pawns on a chessboard controlled by people or forces outside themselves (external locus of control). People who are well educated and wealthy are often in the former category; those who dropped out of high school and are poor are often in the latter category. Trying to tell a poor person that, "You can shape your future any way you want," is often futile. The locus of control research tradition focuses on the question whether you experience control of your life as being internal to yourself or external.

Self-efficacy research is an offshoot of the locus of control research. "Self-efficacy" refers to your capability, competence, effectiveness, mastery, ability, adequacy, influence, performance or success as a person. Albert Bandura (1991, 1994) proposes that you will be better off if you experience yourself as having more self-efficacy (internal locus of control). Such people "quickly recover their sense of efficacy after failures or setbacks. They attribute failure to insufficient effort or deficient knowledge and skills which are acquirable. They approach threatening situations with assurance that they can exercise control over them" (Bandura 1994). Another offshoot from that research is the branch of sports psychology that teaches Olympic athletes to enhance their peak performance by imagining success.

At first glance this research on self-efficacy and locus of control appears to be purely psychological with no spiritual aspect. However, when we examine this research under the 
lamp of ToM, spirituality shines through. If your future is partly controlled by forces outside yourself (be that chance, Providence, or fate), do you think of those external forces as having a mind like yours, or not?

If the answer is "yes," then ToM would classify you as being in the arena of religions that focus on God or a god with a human-like personality. In that case you might feel more in control of your life by figuring out what this god wants, how he or she thinks, and getting yourself attuned to the same wavelength as the god who controls your future. Christians, for example, often feel better when they are desperately ill in a hospital, if they pray. They may feel powerless (i.e., external locus of control, little self-efficacy), but they believe that God hears their prayer. Through prayer they can influence the parent upstairs who controls everything. Thus religion leads to better morale by influencing one's sense of efficacy and locus of control. Powerless people can exert some control by appealing to God, who is in control of everything and who listens to the downtrodden. If the illness gets worse, the patient might conclude that it must be God's will and therefore there is some beneficial aspect embedded in this affliction.

If, on the other hand, the answer is "no," then ToM would classify you as being in the arena of one of the impersonal spiritualities (such as astrology, Buddhism or $q i$ ). Here the key to being upbeat is to recognize that there are forces and laws greater than yourself. You must allow yourself to be swept along by the current whichever way the river of life takes you. You might be able to have some efficacy if you learn how the river flows, but mostly you must relax even though the locus of control is external to yourself.

Most athletes have a favorite tee shirt or batting helmet they wear because they are superstitious. Some go though elaborate rituals before stepping into the batter's box. Others pray before a game. Many athletes do both: they go through some ritual, or carry a totem and they also pray. This is to cover both possibilities: that the outcome of the game is controlled by impersonal luck, or by a personal God who has a Theory of Mind.

These ideas about self-efficacy and locus of control are simply illustrations of the many ways in which ToM provides a new vocabulary that allows us to think about everything in a new light. It also shows that spirituality and psychology could be closely linked together when we examine them from a ToM perspective.

\section{Conclusion}

Our purpose in this article is not to provide new research, nor a definitive statement of anything. Our purpose is more like that of a person bouncing on a trampoline. In this fanciful article we are attempting to loosen up the imagination of the reader, freeing ToM research from being bound to simple questions, challenging the reader to embark on explorations of new aspects of ToM. Previous ToM research focused on simple questions such as, "What is the difference between a child with and a child without ToM?" We propose to focus some future ToM research on complex questions such as, "What is the relationship between religion and health when we adopt ToM as our research method?"

ToM is an empirical science, and it comes with many research questionnaires, technical tools and protocols that could be adopted by those who want to conduct empirical research for their $\mathrm{PhD}$ thesis in spirituality or psychology. In the area of religion and health, ToM based research could be particularly valuable, because there are so few research instruments for reliably classifying and measuring what the words "spirituality" or "religion" mean. 
Open Access This article is distributed under the terms of the Creative Commons Attribution Noncommercial License which permits any noncommercial use, distribution, and reproduction in any medium, provided the original author(s) and source are credited.

\section{References}

Adolphs, R. (2001). The neurobiology of social cognition. Current Opinion in Neurobiology, 11, $231-239$.

Augustine. (1955). Confessions and the enchiridion (trans: A. C. Outler). Philadelphia: Westminster, see enchiridion, chap. 8, par. 27.

Bandura, A. (1991). Self-efficacy mechanism in physiological activation, health-promoting behavior. In J. Madden IV (Ed.), Neurobiology of learning, emotion and affect (pp. 229-270). New York: Raven.

Bandura, A. (1994). Self-efficacy. In V. S. Ramachaudran (Ed.), Encyclopedia of human behavior (Vol. 4, pp. 71-81). New York: Academic Press. (Reprinted in Friedman, H. (Ed.). (1998). Encyclopedia of mental health. San Diego: Academic Press). Available online at http://des.emory.edu/mfp/BanEncy. html, accessed on Feb 9, 2008.

Baron-Cohen, S. (1995). Mindblindness: An essay on autism and theory of mind. Cambridge, MA: MIT Press.

Baron-Cohen, S., \& Bolton, P (1993). Autism: The facts. New York: Oxford University Press.

Baron-Cohen, S., Jolliffe, T., \& Mortimer, C., Robertson, M. (1997). Another advanced test of theory of mind: Evidence from very high functioning adults with autism or Asperger's syndrome. Journal of Child Psychology and Psychiatry, 38, 813-822.

Baron-Cohen, S., Wheelwright, S., Hill, J., Raste, Y., \& Plumb, I. (2001). The 'reading the mind in the eyes' test revised version: A study with normal adults and adults with Asperger's Syndrome or high functioning autism. Journal of Child Psychology and Psychiatry, 42, 241-251.

Boyd, J. H. (2000). The 'soul' of the Psalms compared to the 'self' of Kohut. Journal of Psychology and Christianity, 19, 219-231.

Brothers, L. (1990). The social brain: A project for integrating primate behavior and neurophysiology in a new domain. Concepts in Neuroscience, 1, 27-51.

Brüne, M. (2005). "Theory of mind" in schizophrenia: A review of the literature. Schizophrenia Bulletin, $31(1), 21-42$.

Brüne, M., \& Brüne-Cohrs, U. (2006). Theory of mind-evolution, ontogeny, brain mechanisms, and psychopathology. Neuroscience and Biobehavioral Reviews, 30, 437-455.

Buitelaar, J. K., van der Wees, M., Swaab-Barneveld, H., \& van der Gaag, R. J. (1999). Theory of mind and emotion-recognition functioning in autistic spectrum disorders and in psychiatric control and normal children. Development and Psychopathology, 11, 39-58.

Cheney, D. L., \& Seyfarth, R. M. (2007). Baboon metaphysics: The evolution of a social mind. Chicago: University of Chicago Press.

Cohen, A. (2003). A psychology of liberation: The five fundamental tenets of enlightenment, a poster published by the EnlightenNext World Center, PO Box 2360, Lenox, MA 01240 USA, email: info@EnlightenNext.org.

Cohen, A. (2008a). Andrew Cohen: Twenty-first-century spiritual teacher and pioneer of evolutionary enlightenment, available at http://www.andrewcohen.org/, accessed February 24, 2008.

Cohen, A. (2008b). The fourth tenet: The truth of impersonality, available at http://www.andrewcohen.org/ teachings/impersonality.asp/, accessed February 24, 2008.

Collins, R. (2003). Past worlds: Atlas of archaeology. New York: HarperCollins and Borders Press.

Drubach, D. (2008). The purposes and neurobiology of theory of mind. Journal of Religion and Health.

Humphrey, N. (1984). Consciousness regained. New York: Oxford University Press.

Kanner, L. (1943). Autistic disturbance of affective contact, Nervous Child, 2, 217-250. Reprinted in Kanner, L. (1973), Childhood psychosis: Initial studies and new insights. Wiley.

Kohut, H. (1971). The analysis of the self: A systematic approach to the psychoanalytic treatment of narcissistic personality disorder. Madison, CO: International Universities Press.

Kohut, H. (1984). How does analysis cure? Chicago: University of Chicago Press.

Kohut, H. (1985). Self-psychology and the humanities. New York: W. W. Norton.

Kohut, H. (1990). The restoration of the self. Madison, CO: International Universities Press.

Koenig, H. G., McCullough, M. E., \& Larson, D. (2001). Handbook of religion and health. New York: Oxford University Press.

Meltzoff, A. N., \& Moore, M. K. (1995). A theory of the role of imitation in the emergence of self. In P. Rochat (Ed.), Advances in psychology: Volume 12, The self in infancy: Theory and research (pp. 73-93). Amsterdam, the Netherlands: North Holland/Elsevier. 
Miller, C (2006). Developmental relationships between language and theory of mind. American Journal of Speech-Language Pathology, 15, 142-154.

Moriguchi, Y., Ohnishi, T., Lane, R. D., Maeda, M., Mori, T., Nemoto, K., Matsuda, H., \& Komaki, G. (2006). Impaired self-awareness and theory of mind: An fMRI study of mentalizing in alexithymia. Neuroimage, 32(3), 1472-82.

Oberman, L. M., \& Ramachandran, V. S. (2007). The simulating social mind: The role of the mirror neuron system and simulation in the social and communicative deficits of autism spectrum disorders. Psychological Bulletin, 133(2), 310-327.

Premack, D., \& Woodruff, G. (1978). Does the chimpanzee have a 'theory of mind'. Behavioral and Brain Sciences, 4, 515-526.

Rotter, J. B. (1954). Social learning and clinical psychology. New York: Prentice-Hall.

Rotter, J.B. (1966). Generalized expectancies of internal versus external control of reinforcements. Psychological Monographs, 80 (whole no. 609).

Rotter, J. B. (1975). Some problems and misconceptions related to the construct of internal versus external control of reinforcement. Journal of Consulting and Clinical Psychology, 43, 56-67.

Savina I., \& Beninger, R. J. (2007). Schizophrenic patients treated with clozapine or olanzapine perform better on theory of mind tasks than those treated with risperidone or typical antipsychotic medications. Schizophrenia Research, 94(1-3), 128-138.

Smith, A. (1759). The theory of moral sentiments. Oxford, England: Oxford University Press.

Wade, N. (2007). How baboons think (Yes, think). Science Times, New York Times, section F, pp F1, F4, October 9.

Wolf, E. S. (1988). Treating the self: Elements of clinical self-psychology. New York: Guilford Press. 